\title{
Effects of Habitat Type on the Breeding Density of Barn Swallow (Hirundo rustica)
}

\author{
Sung-Ryong Kang*
}

School of Renewable Natural Resources, Louisiana State University AgCenter, Baton Rouge, LA 70803, United States

\begin{abstract}
A principal aim of habitat selection studies is to understand the roles of the different factors that influence the spatial distribution of individuals. The relationship between microhabitats in farmland, estuary, and island and breeding density of barn swallow are still poorly known. The principal objectives of this study are to compare: i) the proportion of microhabitats in different habitat types and ii) breeding density (i.e., pairs and individuals in a colony) among three habitat types. I hypothesize that i) no microhabitat would be dominant portion across all habitat types and ii) farmland that contains relatively greater portion of crop fields has higher breeding density than estuary and island that relatively greater portion of non-crop fields. Although microhabitats in farmland, estuary, and island revealed clear proportional difference, densities of breeding pair and individual in a colony did not differ.
\end{abstract}

Keywords: Barn swallow, Habitat type, Microhabitats, Breeding densit.

\section{INTRODUCTION}

A principal aim of habitat selection studies is to understand the roles of the different factors that influence the spatial distribution of individuals $[1,2]$. The several explanations of habitat selection patterns include the distribution of nestsite and prey [3]. Other factors also exist that may restrict selection, leading individuals to occupy habitats of lesser quality [1]. In addition, birds are often associated with specific habitats, presumably through the evolution of behavioral affinities for habitat features that are linked to resources necessary for reproduction and survival [4]. In this sense, landscape structure may restrict an individual to occupy a habitat [5]. Intraspecific interaction may also limit space (e.g., nest-site) use of individuals and may restrict them to select optimal habitats [2].

Barn swallows are a generalist species with a wide breeding range, occurring in most lowland landscapes and able to exploit a wide variety of prey types [6]. Their populations widespread in South Korea during breeding season and they generally can find in different habitat types (i.e., farmland, estuary, island) throughout the country. Barn swallow populations had preference habitat types as response to land-use changes [7]. Several studies observed that positive relationship between breeding barn swallow population and the presence of livestock, particularly cattle [8-11]. Another study [12] also noted that the absence of livestock affects detectable differences in the distribution of breeding barn swallow. Although some farmlands have livestock and cattle but no livestock is in the most of estuary and island areas

*Address correspondence to this author at the Rm. 307, RNR Building, Louisiana State University, Baton Rouge, LA 70803; Tel; 1-225-603-7957; Fax: 1-225-578-4144; E-mail: skang1@tigers.lsu.edu that found breeding barn swallow populations in South Korea. Furthermore, the relationship between microhabitats in farmland, estuary, and island and breeding density of barn swallow are still poorly known. I am unaware of studies that have evaluated the relationship between microhabitat and breeding density of barn swallow among farmland, estuary, and island.

A clear understanding of the links between microhabitats and breeding density of barn swallow in different habitat types would enhance our understanding of breeding habitat requirement and of the effects of anthropogenic activities, such as agricultural intensification and microhabitat characteristic alteration (e.g., paddy to ungrazed grassland) on distribution pattern of breeding barn swallow population. The principal objectives of this study are to compare: i) the proportion of microhabitats in different habitat types and ii) breeding density (i.e., pairs and individuals in a colony) among three habitat types. I hypothesize that i) no microhabitat would be dominant portion across all habitat types and ii) farmland that contains relatively greater portion of crop fields has higher breeding density than estuary and island that relatively greater portion of non-crop fields.

\section{MATERIALS AND METHODOLOGY}

This study was conducted in Kimhae plain $\left(35^{\circ} 13^{\prime} 7^{\prime \prime} \mathrm{N}\right.$,

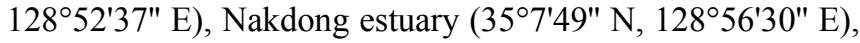

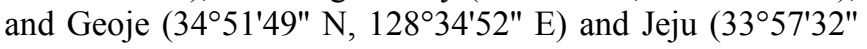
N, $126^{\circ} 17^{\prime} 54^{\prime \prime}$ E) island in South Korea from March 2003 to September 2004. I used main water resource (i.e., salinity: farmland: $0.1-0.5$; estuary: 1.0-8.4; island: $8.1-29.4$ ) around study sites to define the habitat types. Previous studies noted barn swallow foraged at a maximum radius $600 \mathrm{~m}$ distance from their nest $[13,14]$; also, my observation and estimation 
indicated almost all movement occurred within this range (i.e., diameter $1.2 \mathrm{~km}$ ). In each of the three habitat types, all villages identified from aerial photography and field visits and then validated presence of barn swallow colony within radius $600 \mathrm{~m}$. Five microhabitats (i.e., paddy, arable fields, un-grazed grassland, ditch, residential house) were identified and assessed by direct observation and then recorded on the maps. The area of each microhabitat type was measured by aerial photography after field validation. Breeding activity monitored every week and recorded the breeding pairs, the number of complete breeding attempts, and the total number of offspring. Clutch size was defined as the number of eggs laid in succession in a nest. Breeding pair was grouped as: 1) 1-5 pairs; 2) 6-10 pairs; 3) 11-15 pairs; and 4) 16-20 pairs.

Data were tested for normality with the Shapiro-Wilks test for ANOVA analyses. In the event that the residuals were not normally distributed, the data were logtransformed. Data are reported as mean $\pm \mathrm{SE}$, and significance level was chosen at $\alpha=0.05$ or less. ANOVA (Proc Mixed, Version 9.3, SAS Institute, North Carolina) was used to test for statistical differences in microhabitats and breeding density (i.e., pair, individual) by habitat types. Significant ANOVA effects were tested using post-hoc comparisons of Tukey adjusted least squared means. Multiple Linear Regression (Proc Mixed, Version 9.3, SAS Institute, North Carolina) was used to examine the potential relationship between microhabitats and breeding density.

\section{RESULTS}

Paddy proportion in farmland was greater than in estuary and island $\left(\mathrm{F}_{2,21}=10.87, \mathrm{p}<0.01\right)$ but did not differ between estuary and island. Ungrazed grassland and residential house were higher in island than in farmland and estuary, respectively (Ungrazed grassland: $\mathrm{F}_{2,21}=17.62, \mathrm{p}<0.01$; Residential house: $F_{2,21}=8.72, p<0.01$ ). Arable fields and ditch did not differ among habitat types (Table 1).

219 breeding pairs and 921 barn swallows were founded in 24 sites from March-September 2003 and 2004. The highest breeding pair group in different habitat types was 1-5 pairs in all habitat types (Fig. 1). The mean clutch size of

Table 1. Microhabitat Composition (\%) Within a $600 \mathrm{~m}$ Radius, Corresponding to the Breeding Barn Swallow Territories in Farmland (n=10), Estuary (n=30), and Island (n=8) from March 2003-September 2004

\begin{tabular}{|c|c|c|c|}
\hline & Farmland & Estuary & Island \\
\hline \hline Paddy & 66.7 & 13.5 & 8.8 \\
\hline Arable fields & 5.8 & 28.8 & 1.3 \\
\hline Ungrazed grassland & 8.3 & 30.0 & 51.1 \\
\hline Ditch & 3.4 & 1.3 & 0.0 \\
\hline Residential house & 15.8 & 26.4 & 38.8 \\
\hline
\end{tabular}

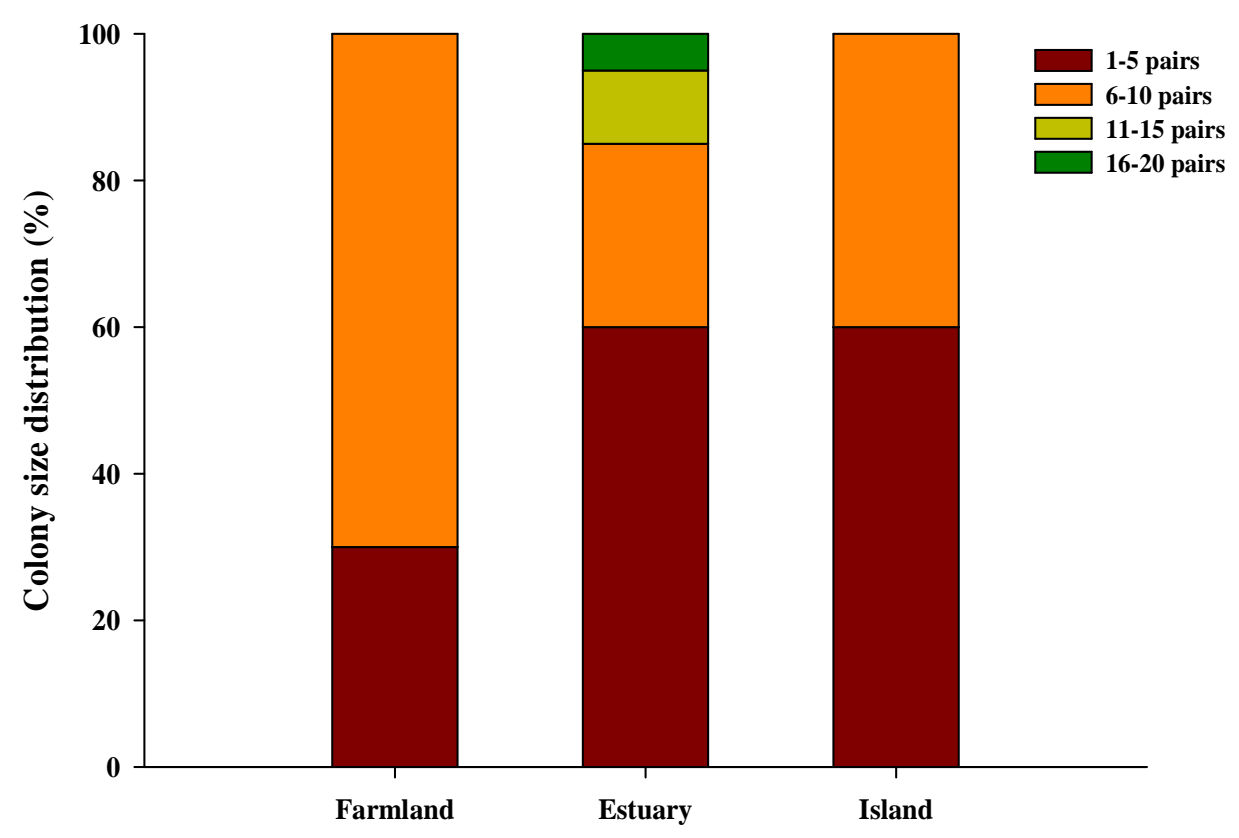

Habitat type

Fig. (1). Distribution (\%) of colony size in farmland, estuary, and island, South Korea. 
breeding pairs was as follows: $4.3 \pm 0.09$ eggs nest $^{-1}$ (mean \pm $\mathrm{SE}$, farmland), $4.2 \pm 0.09$ eggs nest ${ }^{-1}$ (estuary), and $4.2 \pm$ 0.09 eggs nest ${ }^{-1}$ (island). In the clutch size comparison, no statistically differences were observed among three habitat types $\left(\mathrm{F}_{2,216}=0.62, \mathrm{p}=0.54\right)$.

Breeding pair density ranged from $7.0 \pm 0.60$ pair colony ${ }^{-}$ ${ }^{1}$ (farmland) to $5.5 \pm 0.50$ pairs colony ${ }^{-1}$ (island). Similar to breeding pair density pattern, the mean number of breeding individuals in each colony ranged from $30.1 \pm 3.10$ individuals colony ${ }^{-1}$ (farmland) to $23.7 \pm 3.35$ individuals colony $^{-1}$ (island). Both breeding pair $\left(\mathrm{F}_{2,3}=2.57, \mathrm{p}=0.22\right)$ and individual density $\left(\mathrm{F}_{2,3}=1.50, \mathrm{p}=0.35\right)$ in farmland, estuary, and island did not statistically differ, respectively. In addition, no statistically significant relationships were observed between microhabitats and breeding pair/individual density.

\section{DISCUSSION}

I could find clear differences in microhabitat proportion among farmland, estuary, and island breeding sites. The most obvious different microhabitat proportions in different habitats were paddy and residential house. The proportion of paddy was decreasing inland (i.e., farmland) towards the ocean (i.e., island) and increasing residential house portion in the opposite direction. Although microhabitats in farmland, estuary, and island revealed clear proportional difference, densities of breeding pair and individual in a colony did not indicate any differences.

I did not consider aerial invertebrate abundance in this study although invertebrates can affect the distribution of foraging barn swallows. Aerial invertebrate abundance varied markedly across different field types (e.g., pasture, silage, cereal, [14]). For instance, abundance of aerial invertebrate in pasture fields was two to seven times that over cereal and two to three times that over silage, the difference increasing later in the season due to cereal and silage fell [14]. In addition, barn swallows exploited different prey types during different phases of their breeding season [7,15], and so may benefit from the differential seasonal development of several crops or grasses in potential foraging sites. In this sense, relatively abundant portion of particular microhabitat in farmland, estuary, and island may influence breeding density of barn swallow as potential driving factor that is associated with prey abundance. No statistically significant difference of breeding pair and individual density across farmland, estuary, and island suggested that three habitat types may have similar abundance of aerial invertebrates and fitness as breeding habitat.

The second hypothesis that farmland that contains relatively greater portion of crop fields has higher breeding density than estuary and island that relatively greater portion of non-crop fields was not supported. The lack of a difference detected among breeding density in different habitat types may be influenced by relatively small sample size. However, this finding may suggest different composition of microhabitats in three habitat types may not strongly affect breeding density (pairs and individuals).
In conclusion, this study investigated the effect of breeding habitat type on breeding density (pairs and individuals) and nest-sites distribution of barn swallow population, and showed that farmland, estuary, and island had different proportion of microhabitats but breeding density did not differ among three habitat types. The comparison of breeding density with microhabitat composition in different habitat types can be used to support a wide range of habitat assessment requirements for a long-term monitoring of barn swallow population dynamic. Developing predictive model that are accurate and incorporate is important for providing useful assessment tools to land managers and owners. This study may provide an objective quantifiable method of assessing the existing habitat conditions by measuring how well each habitat variable meets the habitat requirements for breeding barn swallow population.

\section{CONFLICTS OF INTEREST}

The authors confirm that this article content has no conflicts of interest.

\section{ACKNOWLEDGEMENTS}

This project was supported by a Dong-A University in South Korea. I would like to acknowledge to KC. Kwon, R. Safran, and B. Pickens for their critical insights. I am also very grateful to all the farm owners who kindly provided houses and crop fields for the census.

\section{REFERENCES}

[1] Morris DW. Toward an ecological synthesis: a case for habitat selection. Oecologia 2003; 136: 1-13.

[2] Sanza MA, Traba J, Morales MB, Rivera D, Delgado MP. Effects of landscape, conspecifics and heterospecifics on habitat selection by breeding farmland birds: the case of the Calandra Lark (Melanocorypha calandra) and Corn Bunting (Emberiza calandra). J Ornithol 2012; 153: 525-33.

[3] Morris DW, Davidson DL. Optimally foraging mice match patch use with habitat differences in fitness. Ecology 2000; 81: 2061-6.

[4] Steels BB. Selection of foraging and nesting sites by black-throated blue warblers: Their relative influence on habitat choice. Condor 1993; 95: 568-79.

[5] Lima SL, Zollner PA. Towards a behavioral ecology of ecological landscapes. Trends Ecol Evol 1996; 11: 131-5.

[6] Turner AK. The Barn Swallow. London, Poyser: A \& C Black 2006.

[7] Henderson I, Holt C, Vickery J. National and regional patterns of habitat association with foraging Barn Swallows Hirudo rustica in the UK. Bird Study 2007; 54: 371-7.

[8] Møller AP. The effect of dairy farming on Barn Swallow Hirudo rustica abundance, distribution and reproduction. J Appl Ecol 2001; 38: 378-89.

[9] Ambrosini R, Bolzern AM, Canoval L, Arieni S, Møller AP, Saino N. The distribution and colony size of barn swallows in relation to agricultural land use. J Appl Ecol 2002; 39: 524-34.

[10] Evans KL, Robinson RA. Barn Swallows and agriculture. Br Birds 2004; 97: 218-30.

[11] Ambrosini R, Saino N. Environmental effects at two nested spatial scales on habitat choice and breeding performance of barn swallow. Evol Ecol 2010; 24: 491-508.

[12] Evans KL, Bradbury RB, Wilson JD. Selection of hedgerows by barn swallows Hirudo rustica foraging on farmland: the influence of local habitat and weather. Bird Study 2003; 50: 8-14.

[13] Bryant D, Turner A. Central place foraging by Swallows (Hirundinidae): the question of load size. Anim Behav 1982; 30: 84856. 
[14] Evans KL, Wilson JD, Bradbury RB. Effects of crop type and aerial invertebrate abundance on foraging barn swallows Hirudo rustica. Agric Ecosyst Environ 2007; 122: 267-73.
[15] Turner AK. The use of time and energy by aerial feeding birds. $\mathrm{PhD}$ thesis, University of Stirling UK 1980.

Received: July 26, 2012

Revised: October 10, 2012

Accepted: October 14, 2012

(C) Sung-Ryong Kang; Licensee Bentham Open.

This is an open access article licensed under the terms of the Creative Commons Attribution Non-Commercial License (http://creativecommons.org/licenses/by-nc/3.0/) which permits unrestricted, non-commercial use, distribution and reproduction in any medium, provided the work is properly cited. 